\title{
ИНТЕГРАЦИЯ СОВРЕМЕННЫХ ИНФОРМАЦИОННЫХ ТЕХНОЛОГИЙ КАК МЕТОД СОВЕРШЕНСТВОВАНИЯ ОБРАЗОВАТЕЛЬНОГО ПРОЦЕССА В ВЫСШИХ УЧЕБНЫХ ЗАВЕДЕНИЯХ
}

\author{
Д. А. Петров \\ Московский гуманитарный университет
}

\begin{abstract}
Аннотация: Инновационное развитие экономики России обусловило модернизацию во всевозможных сферах. Внедрение инновационных разработок, активное использование достижений IT-индустрии, все это является толчком для развития в условиях инновационной экономики. Эти тенденции также затронули и систему образования.

Текст доклада автора на Общероссийской (национальной) научной конференции «Моисеевские чтения. Культура и гуманитарные проблемы современной цивилизации», которая состоялась 4-5 марта 2020 2. в Московском гуманитарном университете.

Ключевые слова: образовательная услуга; высшее учебное заведение; образовательный процесс; IT-образование; геймификация; фластильный класс
\end{abstract}

\section{INTEGRATION OF MODERN INFORMATION TECHNOLOGIES AS A METHOD OF IMPROVING THE EDUCATIONAL PROCESS IN HIGHER EDUCATION INSTITUTIONS}

\author{
D. A. Petrov \\ Moscow University for the Humanities
}

Abstract: The innovative development of Russian economy has led to modernization in various areas. The introduction of innovative developments, active use of the achievements of the IT industry, all this is an impetus for development in an innovative economy. These trends also affected the education system.

The text of the author's speech at the All-Russian (National) Scientific Conference "Moiseev's Readings. The Culture and Humanitarian Issues of Modern Civilisation", which was held at Moscow University for the Humanities on 4-5 March, 2020.

Keywords: educational service; higher educational institution; educational process; IT education; gamification; flastile class

В реалиях современного мира, когда IT-технологии применяются практически в каждой сфере деятельности, встает вопрос их внедрения в более традиционные элементы деятельности человека - образовательные процессы. Применение инновационных технологий и сопутствующих изменений позволяет кардинально изменить как сам процесс обучения, так и значительно повысить качество его исполнения, переведя некоторые элементы образовательного процесса на совершенно другой уровень. Иначе говоря, сегодня технологии позволяют значительно облегчить взаимодействие между преподавателем и учеником, а также позволяют повысить качество непосредственно образования.

Последствия внедрения могут косвенно изменить ряд ключевых аспектов образовательного процесса: 
• контроль и повышение качества образовательных услуг;

- более широкая вариативность подачи материала;

- новые методы коммуницирования;

- инновационные возможности хранения и обмена информацией;

- повышение вовлеченности субъектов процесса обучения (преподаватель, обучающийся, родитель).

Говоря о тенденциях изменения образовательных программ, обратимся к заявлению заместителя министра науки и высшего образования РФ Дениса Солодовникова в 2019 г. Согласно ему, к концу 2024 г. 20\% студентов будут осваивать отдельные курсы и дисциплины онлайн, с использованием ресурсов образовательных организаций и университетов, обеспечивающих соответствие качества подготовки обучающихся мировому уровню.

Наданный момент существует множествоэффективныхрешений,позволяющих модифицировать образовательные услуги на технологическом уровне. Предлагаю рассмотреть ряд современных решений совершенствования образовательных процессов на примере трех моделей образования.

Интерактивное образование или модели Образование 1.0-4.0. В основе данных образовательных систем заложена сугубо педагогическая цель. Инновационные средства коммуникации в данном случаеявляются исключительно технологической возможностью улучшения образовательных услуг.

В самом начале, версия Образование 1.0 являлось классической моделью образовательного процесса, основанной на трех процессах:

- слушать, фиксировать и изучать;

- отвечать на вопросы;

- стремиться получать высокие оценки.

Обучающиеся уже являлись потребителями образовательныхуслуг и к ним применяется стандартизированный подход, сформированный с учетом наибольшего охвата потребителей.

Обучающиеся зависели от преподавателей и учебных пособий как от основных носителей информации. Эта педагогическая модель обучения и сегодня является преобладающей на всех уровнях образования. В сегодняшних условиях образовательной среды и с учетом технологий возможно:

- обеспечение доступа к информации онлайн;

- предоставление условий для взаимодействия напрямую с материалами;

- возможность получить быструю обратную связь.

Следующим этапом технологического роста является модификация модели Образование 2.0. Главным нововведением было интерактивное взаимодействие с контентом и другими пользователями. Другими словами, был осуществлен переход от доступа к информации к интерактивному взаимодействию посредством онлайнисточников и социальных сетей, как метода взаимодействия (Гольдин, 2010).

Образование 2.0 подразумевает более активное взаимодействие между субъектами образовательного процесса и контентом. Практиковались методы перехода к более творческому образованию за счет использования проектов, кооперативного обучения, реализации масштабных учебных проектов, использования современных средств связи, онлайн-статей и других возможностей.

Образование 3.0 является унифицированной и интерактивной подачей кон- 
тента. Оно основано на понятии персонализированного, самоопределяющегося образования. Определение области знаний, где объединяются решения, инновации и творчество.

Нововведения в систему обучения возникают возможности для более глобальных связей. Для осуществления перехода к ступени Образования 3.0 должны быть соблюдены следующие условия:

- образование являет собой многообразии мнений;

- обучение есть процесс использования специализированных ресурсов и источников информации;

- обучение может проходить в условиях цифрового обучения;

•достоверные, новейшие знания служат валютой и результатом учебной деятельности;

- выбор программ рассматривается сквозь призму изменяющейся реальности. Решение может стать неправильным завтра из-за происходящих изменений.

Открытость этой образовательной системы предоставляет каждому возможность самостоятельного выбора своего образовательного процесса, группы для занятий и видов деятельности. Однако открытость не способна регламентировать образовательный процесс учебным планом и образовательной программой - в образовании эти документы играют совершенно другую роль, регламентируя не деятельность учащихся, а условия и порядок предоставления образовательных услуг (Gerstein, 2004).

Таким образом, IT позволяют создать среду компьютерной и коммуникационной поддержки. Сегодня в таких сферах деятельности, как образовательная, появились готовые комплексные и проверенные решения - образовательные комплексные платформы, такие как Образование 4.0.

Сам процесс становления образовательных программ, описываемый выше, является информатизацией образования. Т. е. приведение системы образовательных процессов к потребностям и удобствам современного их потребителя.

Последствиями введения в ИКТ являются:

- контролируемые информационные источники;

• инструменты поиска информации и работы с ней;

- поддержка и модернизация учебного процесса;

- создание учебного плана, его оптимизация и прозрачность;

- современные системы контроля и направления учебного процесса.

В качестве основных направлений изучения и использования IT на первой ступени обучения, как правило, выступают следующие:

- $\quad$ формирование основных теоретических аспектов для понимания сути информации и работы с ней;

- понимание навыков работы с информацией: ее поиск и классификация, упорядочивание и хранение;

- понимание основ информационной безопасности;

- освоение информационных средств и средств коммуникации развитие навыков работы с самыми распространенными и востребованными инструментами (редактирование текста, графическая подача информации, визуализация);

- понимание работы инструментов коммуникации и сети Интернет.

Таким образом, в сфере высшего образования, в силу работы с более развитой аудиторией, практическая часть обучения все чаще переходит в работу за учебным 
ПК, также это касается и новых возможностей контроля и тестирования знаний обучающихся.

Тем не менее, необходимо упомянуть, что развитие технологий также влечет ряд проблем.

Во-первых, возникает необходимость предварительной подготовки к их применению. Для сферы высшего образования означает необходимость в профильной подготовке кадрового состава.

Во-вторых, модернизация образовательных процессов зачастую заторможена по таким причинам, как нужда в переносе на цифровые носители, низкая вовлеченность со стороны старшего преподавательского состава.

Несмотря на это, самые современные технологии способны не только повысить вовлеченность, но и полностью перестроить процесс обучения.

Кроме взаимодействия с современными информационными технологиями существует ряд образовательных практик, позволяющих переосмыслить процесс преподавания с точки зрения взаимодействия с обучаемыми, повышения уровня вовлеченности и качества усвоения материала.

Геймификация. Это набирающая популярность методология использования и внедрения в образовательные процессы игровых элементов. В данном случае это может быть не только психологический фактор для вовлечения в образовательный процесс, но и элемент электронного обучения, состоящий из ряда игровых механик, основанных на положительном субъективном опыте субъекта-участника, который заимствован из игр.

Существует целый спектр различных решений, а его содержание зависит от фантазии создателя. Наиболее показательный и практичный - квестовый элемент. В данном случае механика позволяет перестраивать образовательный процесс для любой группы обучающихся в зависимости от возраста, особенностей, целей обучения и потребностей обучающихся.

Исследования выделили области, в которых геймификация демонстрирует благоприятное влияние на обучающихся:

- Вовлеченность учащихся в процесс обучения;

- Повышенная мотивированность в достижении результата;

- Концентрация за счет интереса на процессе усвоения материала;

- Развитие навыков решения проблем нестандартными путями.

Данный вид обучения, как унаследованная модель работы с детьми, предполагает гораздо более глубокий и эффективный уровень взаимодействия с обучаемыми любых возрастных групп, чем классические, более пассивные действия.

Фластильные классы. Иначе говоря, это - «перевертывание» модели обучения: меняются местами элементы лекции и домашнего обучения. Опыт обучения в аудитории меньше опирается на пассивное аудиально-визуальное обучение и приоритезирует участие в образовательном процессе. Данная концепция образовательного процесса подразумевает возможность потреблять теоретический материал в наиболее комфортной обстановке для обучающегося. Это, в свою очередь, позволяет преподавателям оптимизировать время в аудитории и уделить внимание иным видам деятельности.

В сочетании с современными возможностями онлайн-образования этапы теоретического обучения и проверки знаний могут быть адаптированы в любом 
необходимом виде, что также способствует более глубокой отработке трудностей и практическому усвоению.

Вывод. Задача любых инноваций - облегчить жизнь человека. Это, несомненно, качественно отображается на возможностях современного образования. Однако не стоит упускать тот факт, что технологии необходимы лишь для улучшения уже существующего образовательного процесса, что делает акцент на необходимости оптимизировать процесс заранее. Только избрав наиболее оптимальное решение и путь модернизации, следует рассмотреть их преимущества и недостатки, а также всесторонне изучить потенциальные последствия их использования.

\section{СПИСОК ЛИТЕРАТУРЫ}

Гольдин, А. М. (2010) Образование 2.0: модный термин или новое содержание? // Вопросы образования. № 2. С. 224-238.

Gerstein, J. (2004) Moving From Education 1.0 Through Education 2.0 Towards Education 3.0. / Blaschke L., Kenyon C., Hase S. (Eds.). Experiences in Self-DeterminedLearning [Электронный ресурс] // Create Space Independent Publishing Platform, 2014. P. 83-98. URL: https://usergeneratededucation.wordpress.com/2014/12/01/ experiences-in-self-determined-learning-moving-from-education-1-0-through-education-2-0-towards-education-3-0/ (дата обращения: 02.02.2020).

Дата поступления: 30.03.2020 г.

Петров Денис Андреевич - магистрант второго курса обучения по направлению "Современные маркетинговые коммуникации" Московского гуманитарного университета. Адрес: 111395, Россия, г. Москва, ул. Юности, д. 5. Тел.: +7 (962) 171-03-42. Эл. адрес: def.not.den@yandex.ru

Petrov Denis Andreevich, Graduate Student, academic programme "Modern Marketing Communications", Moscow University for the Humanities. Postal address: 5, Yunosti St., Moscow, Russian Federation, 111395. Tel.: +7 (962) 171-03-42. E-mail: def. not.den@yandex

\section{Для цитирования:}

Петров Д. А. Интеграция современных информационных технологий как метод совершенствования образовательного процесса в высших учебных заведениях // Научные труды Московского гуманитарного университета. 2020. №2. C. 4-8. DOI: 10.17805/trudy.2020.2.1 